\title{
Barbosa Jr., Ademir. O corte: provocações sobre o abate religioso. São Paulo: Pluralidades, 2020.44p.
}

\author{
PATRÍCIO CARNEIRO ARAÚJO
}

UNIVERSIDADE DA INTEGRAÇÃO INTERNACIONAL DA LUSOFONIA AFRO-BRASILEIRA (UNILAB), REDENÇÃO/CE, BRASIL HTTP://ORCID.ORG/OOOO-OOOI-590I-945X

O abate religioso de animais é uma prática presente em várias expressões religiosas. Considerando o campo religioso brasileiro, judaísmo, islamismo, candomblé e umbanda são algumas das religiões que mantém essa prática como parte constitutiva do seu arcabouço litúrgico e ritualístico. Curiosamente, nos últimos tempos tem havido muitas tentativas de criminalizar essa ação, quando realizada pelos afro-religiosos. Uma querela em torno da constitucionalidade dessa prática (Recurso Extraordinário 494.601), que começou no Rio Grande do Sul, chegou ao Supremo Tribunal Federal e teve fim no ano de 2019 é um bom exemplo de como o abate religioso de animais tem sido alvo de questionamentos. Mesmo algumas lideranças das religiões afro-brasileiras têm levado a cabo movimentos de revisão dessa prática, despertando a curiosidade da academia e a reação de religiosos mais ortodoxos.

As ciências humanas e sociais - ainda mais a Antropologia da Religião -, sempre se interessaram pelo tema do sacrifício, sendo este um dos seus temas de pesquisa prediletos. Eu mesmo analisei parte desses movimentos no livro intitulado Candomblé sem sangue? Pensamento ecológico contemporâneo e mudanças rituais na religiões afro-brasileiras, quando discuti algumas das motivações endógenas e exógenas ao candomblé que têm levado à supressão do uso de sangue animal nessas religiões e a sua substituição por outras matérias também tidas como portadoras de sacralidade. Tanto a justificativa quanto a explicação da abolição desses usos aparecem não só nos estudos acadêmicos, mas também numa literatura que surge a partir daqueles que lideram esses movimentos. Tal produção pode ser muito útil aos pesquisadores para melhor compreender os sentidos atribuídos a essas mudanças tão profundas nos complexos ritos dessas religióes.

O corte: provocações sobre o abate religioso, de autoria de Ademir Barbosa Jr. (Pai Dermes), lançado em julho de 2020 no Brasil, pela editora Pluralidades, pode ser compreendido como o que há de mais atual na literatura endógena referente às religiões afro-brasileiras, no que diz respeito às discussões suscitadas pelos movimentos revisionistas que propõem a abolição do abate religioso nessas religiões e que têm se disseminado por diferentes regióes do país. 
O livro é composto por 44 páginas, nas quais estão distribuídas uma Introdução (:7), uma primeira parte, constituída pelo capítulo intitulado "O corte como fundamento" (:9-25), uma segunda parte, composta pelo capítulo ao qual o autor chamou "O fundamento sem corte" (:27-35), as referências bibliográficas (:37-38) e um significativo Anexo (:39-43), contendo um depoimento da Iyá Senzaruban, ialorixá do Ilê Axé Iyá Tundê, terreiro de candomblé ao qual o autor pertence e que reivindica o pioneirismo na abolição do abate religioso de animais.

Antes mesmo da Introdução, na página 5 (que no livro não aparece numerada), a dedicatória não deve passar despercebida aos leitores, principalmente àqueles que se dedicam a pesquisar essas religiões. Nesta, Barbosa Jr., numa sugestiva atitude, dedica o livro "Para as iabassês, cozinheiras que sacralizam sabores e saberes". Como se pode perceber, a dedicatória estabelece uma relação direta entre o conteúdo do livro e o campo da alimentação no mundo dos terreiros, direcionando, já no início, o público com quem o autor deseja dialogar. A relação criada também entre o abate religioso e as iabassês não deixa dúvidas de que o sacrifício ritual de animais possui um estreito vínculo com as culturas alimentares dos terreiros.

Depois de anunciar o conteúdo do livro - uma leitura dialética do abate religioso nas religióes tradicionais de terreiro -, o autor também comunica na Introdução seu desejo de que haja um respeito mútuo entre os praticantes das diferentes modalidades de religiões afro-brasileiras e evoca a população afro-religiosa a pensar essa prática a partir das diferentes formas de cultuar as divindades, seja com ou sem o uso de sangue animal. Em suas palavras: "Meu maior desejo é que o livro fomente o respeito entre os irmãos que praticam, ou não, o corte e abra caminhos informativos para pesquisadores e o público em geral". (:7).

Na primeira parte da obra, Barbosa Jr. explica em que consiste o corte e seus significados nas religiões afro-brasileiras, apresentando também um resumo das críticas a essa prática e expondo o que seria a base para essa crítica do senso comum: a negação da sacralidade do ato, acusação de crueldade, confusão com as categorias dos animais utilizados no corte e atribuição equivocada de formas não praticadas de corte, envolvendo imposição de sofrimento aos animais. Para o autor, tais críticas, além de revelarem a ignorância sobre o corte, também refletem a perseguição a essas religiões, incentivada por uma mentalidade preconceituosa, perceptível no livro Orixás, caboclos e guias: deuses ou demônios (1997), de Edir Macedo, bispo da Igreja Universal do Reino de Deus, de orientação neopentecostal.

Barbosa Jr. discorre a respeito do corte praticado no candomblé e já abolido em muitas expressões da umbanda. Contudo, tem o cuidado de alertar para o fato de algumas dessas comunidades religiosas ainda manterem o corte, inclusive com o aval das entidades espirituais que, em casos extremos, o exigem para salvar a vida de alguém, como ele explica na página 14. A partir da página 15, tem-se a discussão da relação entre o corte e o consumo de carne. Grosso modo, o autor, mesmo afirmando não praticar o corte, defende respeito à prática, já que esta, dentre outros aspectos, estaria associada à soberania alimentar das populações afro-religiosas, como defendem os religiosos e pensadores que ele mobiliza para respaldar sua argumentação: Iyá Omindarewa, Mãe Stella de Oxósse, Pierre Verger, Raul Lody e outros. Àqueles que discordam da prática, Barbosa Jr. lembra que o axé presente no sangue também pode ser encontrado em outros elementos da natureza, seja do reino animal, vegetal ou mi- 
neral (:19). Ele termina essa parte reafirmando que a Constituição Federal de 1988, em seu artigo $5^{\circ}$, assegura a liberdade religiosa e de crença, motivo pelo qual projetos de lei de proibição do corte, como o que fora aprovado em Piracicaba (SP), em 2010, não pode se efetivar.

$\mathrm{Na}$ segunda parte do livro, Barbosa Jr. reafirma a figura de Agenor Miranda como o principal responsável pelo embasamento teológico do abandono da prática do corte nos terreiros. Após citar Agenor, menciona o babalawô cubano Alawowwo Samyer Phurull, vindo ao Brasil recentemente para divulgar um modelo de culto aos orixás sem uso de sangue animal. À figura desses dois sacerdotes ele liga duas sacerdotisas: Iyá Senzaruban e Mãe Solange Buonocore, ambas com terreiro em São Paulo e responsáveis pela abolição do uso do corte.

Para o autor, não há dúvidas: mesmo sendo Agenor Miranda o precursor, quem primeiro aboliu o uso de sangue no candomblé no Brasil, foi sua ialorixá: Iyá Senzaruban. Isso teria se dado em 1992, 25 anos antes de Mãe Solange anunciar sua primeira iaô iniciada sem sangue, em seu terreiro de Guarulhos. Estaria resolvida a questão do pioneirismo. E o autor comprova isso explicando que "[...] o primeiro iaô sem cortes (hoje Ebômi Tata Mutaladecy) foi feito por Iya Senzaruban em 1992. E, desse momento até agosto de 2019, contam-se 10 ogãs, 05 equedes, 22 iaôs, 12 ebômis, 09 ialorixás e 01 babalorixá preparados por Iya Senzaruban no Ilê Iya Tundê”. (:30). Depois disso, Barbosa Jr. trata rapidamente dos elementos que substituem o sangue nesse novo modelo de culto, e afirma que, mais difícil do que convencer os orixás com a nova dieta, é dialogar com os próprios religiosos que não admitem abdicar do corte. Outro esforço feito por ele é o de dissociar o candomblé sem corte dos modelos de dietas vegetarianas e veganas. Para tanto, assegura que uma coisa não está necessariamente ligada a outra, fato comprovado pelas falas de Mãe Solange e Iyá Senzaruban.

Todas as informações apresentadas por Barbosa Jr. são confirmadas pela Iyá Senzaruban, em um depoimento concedido ao autor, exclusivamente para o livro, em 04/08/2019. A declaração é muito expressiva e elucidadora, trazendo dados biográficos dessa ialorixá que explicam como os próprios orixás resolveram não aceitar mais o uso de sangue em seu culto. Por esse motivo, é fundamental ler o Anexo para se compreender o conjunto da obra.

No livro, o reduzido número de páginas e a simplicidade da linguagem utilizada não devem ser confundidos pelo leitor apressado. Trata-se de um importante marco nas discussões acerca do processo de abolição do sacrifício de animais em algumas expressões afro-religiosas que tem despertado muitos debates dentro e fora dos terreiros. O fato de Barbosa Jr. ser um sacerdote e intelectual, que há muito tempo vem pensando sobre a religião, inclusive por meio da edição de livros e de discussões em diferentes mídias, aumenta ainda mais a importância de sua publicação. Suas ideias apresentam um grande potencial de subsidiar a discussão entre religiosos e pesquisadores, além de apresentar o marco temporal e contextual exato da abdicação do uso de sangue no candomblé. Segundo ele, não pode haver dúvidas: foi Iyá Senzaruban quem primeiro adotou essa prática de forma mais organizada. Também foi ela a primeira a assumir isso publicamente. Mãe Solange Buonocore só viria a público nesse sentido 25 anos depois de Senzaruban.

Outro mérito do livro é demonstrar que se a abolição do sacrifício não é consenso entre os religiosos, sua prática também não é. De certa forma, os grupos apenas adotariam aquilo que a tradição 
lhes passou, mesmo que em alguns casos discordem dela. Barbosa Jr. repete ao longo do livro sua disposição em dialogar com seus pares. Isso nos leva a entender que, em se tratando dessas mudanças no campo afro-religioso, as práticas ligadas ao uso do abate religioso encontram-se em acaloradas negociações. Nesse sentido, nem é possível dar uma palavra final a respeito delas e nem prever como tudo será daqui a dez anos, por exemplo. Porém, uma das conclusões que se pode tirar do livro deste intelectual e sacerdote é que, independentemente do posicionamento pessoal, fica cada vez mais difícil manter-se indiferente a essa questão.

Patricio Carneiro Araújo é Doutor em Ciências Sociais pela Pontifícia Universidade Católica de São Paulo (PUC/SP) e professor da Universidade da Integração Internacional da Lusofonia Afro-Brasileira (UNILAB). Em 2020 realizou pós-doutorado em Antropologia Social na Universidade Federal do Rio Grande do Norte (UFRN).

RECEBIDO: $31 / 08 / 2020$

APROVADO: 05/01/2021 